OPEN ACCESS

Edited by:

Min Ye,

Peking University, China

Reviewed by:

Rufeng Wang,

Beijing University of Chinese Medicine,

China

Jia-bo Wang,

Fifth Medical Center of the PLA

General Hospital, China

*Correspondence:

Guibo Sun

sunguibo@126.com

Yun Q

yqi@implad.ac.cn

Specialty section:

This article was submitted to

Ethnopharmacology,

a section of the journal

Frontiers in Pharmacology

Received: 19 March 2019 Accepted: 25 November 2019

Published: 09 January 2020

Citation:

Gao Y, Qi R, Zhang X, Xu X, Han Y,

Fei $Q$, Wang $X$, Cai $R$, Sun $G$ and Qi $Y$

(2020) Qing-Kai-Ling Injection

Induces Immediate Hypersensitivity

Reaction via The Activation

of Anaphylatoxin C3.

Front. Pharmacol. 10:1524.

doi: 10.3389/fphar.2019.01524

\section{Qing-Kai-Ling Injection Induces Immediate Hypersensitivity Reaction via the Activation of Anaphylatoxin C3}

\author{
Yuan Gao ${ }^{1}$, Ruijuan $Q i^{1}$, Xiaoyu Zhang ${ }^{1}$, Xudong Xu ${ }^{1}$, Yixin Han ${ }^{1}$, Qiaoling Fei ${ }^{1}$, \\ Xiaojing Wang ${ }^{2}$, Runlan Cai ${ }^{1}$, Guibo Sun ${ }^{1 *}$ and Yun $\mathrm{Qi}^{1 *}$ \\ ${ }^{1}$ Institute of Medicinal Plant Development, Chinese Academy of Medical Sciences \& Peking Union Medical College, Beijing, \\ China, 2 Institute of Materia Medica, Chinese Academy of Medical Sciences \& Peking Union Medical College, Beijing, China
}

Background and Objective: Qing-Kai-Ling (QKL) is derived from a famous ancient Chinese patent medicine Angong Niuhuang pills (ANP) which has been used across Asia, especially in China, for the treatment of "febrile disease," such as stroke, encephalitis and meningitis for hundreds of years. As an extract of ANP without heavy metal, the clinical applicability of QKL is more intensive, of which its injection is commonly used in acute and serious diseases. This study aims to clarify the potential mechanisms of immediate hypersensitivity reaction (IHR) induced by $\mathrm{QKL}$ injection (QKLI).

Methods: $\beta$-hexosaminidase release assay was performed on the human mast cell line LAD2 and mouse peritoneal mast cells. T helper 2 (Th2) immunity-amplified mice were prepared by aluminum adjuvant. Anaphylactic shock was detected by measuring rectal thermometry in propranolol-pretreated mice. For evaluating microvascular permeability, Evans Blue extravasation assay was used. Serum total lgE (tlgE) and the activated complement-derived anaphylatoxin C3 (C3a) levels were measured by ELISA.

Results: QKLI was unable to elevate serum tlgE level in the Th2 immunity-amplified mice, but can increase vasopermeability and trigger anaphylaxis after the first injection. By screening seven fractions of QKLI, only the extract of Isatidis Radix (Isatis tinctoria L.) induced hindpaw Evans Blue extravasation, which was disappeared in Isatidis Radix-free QKLI. Mechanism study indicated that QKLI or Isatidis Radix-caused IHR could be blocked by the antagonists for histamine or C3a, rather than PAF or C5a. Consistently, QKLI and Isatidis Radix could also directly activate human serum complement-derived anaphylatoxin 3 (C3) in vitro with the half effective concentration values of $0.69 \%$ and $218.6 \mu \mathrm{g} / \mathrm{ml}$, respectively.

Conclusion: QKLI-IHR is complement activation-related pseudoallergy, rather than an IgE-mediated allergy. QKLI activates C3 and might consequently provoke mast cells to release histamine, which is a principal effector of its IHR. The pseudoallergic reaction induced by QKLI was attributed to the extract of Isatidis Radix. This study suggests a potential therapeutic strategy for the prophylaxis and treatment of QKLI-IHR.

Keywords: Qing-Kai-Ling injection, histamine, complement-derived anaphylatoxin C3, IgE, immediate hypersensitivity reactions 


\section{INTRODUCTION}

Qing-Kai-Ling injection (QKLI), a notable antipyretic preparation, is derived from Angong Niuhuang pills (ANP). ANP is a famous ancient Chinese patent medicine for the treatment of "febrile disease," and has been used across Asia, especially in China, for treating stroke, encephalitis and meningitis (Fu et al., 2017) for hundreds of years. For containing heavy metal (realgar and cinnabar), ANP is forbidden in the USA and European countries (Liu et al., 2008a; Liu et al., 2008b). As an extract of ANP without heavy metal (Topic Study Group in Beijing College of Traditional Chinese Medicine, 1975), Qing-Kai-Ling (QKL) is widely used for the treatment of the upper respiratory inflammation, pneumonia, viral encephalitis and high fever (Gao et al., 2018) and listed in the Chinese Pharmacopoeia (State Pharmacopoeia Committee, 2015). Its components include Isatidis Radix (Isatis tinctoria L.), Lonicerae japonicae Flos (Lonicera japonica Thunb.), Gardeniae Fructus (Gardenia jasminoides J.Ellis), powdered buffalo horn, Concha Margaritifera Usta, cholic acid, hyodeoxycholic acid and baicalin. Perhaps the change in the traditional drug-delivery way (p.o.) brings increasing rapidly cases of adverse drug reaction (ADR) (Li et al., 2010), and an alarm over QKLI-caused potential risks in patients was released by the Chinese National Center for Adverse Drug Reaction Monitoring in June 2008 and April 2009, respectively (National Center for ADR Monitoring, 2008; National Center for ADR Monitoring, 2009). In fact, QKLI is the second leading cause of ADRs induced by traditional Chinese medicine injections (Zhang et al., 2016).

Immediate hypersensitivity reaction (IHR) can be divided into allergic- and non-allergic (NA)-mediated (Johansson et al., 2001), while "anaphylaxis" is reserved for severe IHR (Johansson et al., 2004). Drugs are the most common anaphylaxis triggers in adults (Aun et al., 2017). Among QKLI-induced ADRs, IHR accounted for the largest proportion (Zhong et al., 2012). Accordingly, many researchers have focused on QKLI-induced IHR (QKLI-IHR). Some researchers speculated that QKLI caused allergic-IHRs based on the increased total $\operatorname{IgE}(\mathrm{tgE})$ level in the serum of the QKLI-caused anaphylaxis patients (Zhao et al., 2011), while others thought that QKLI-IHR was a non-immune mediated reaction by virtue of the unchanged plasma tIgE level in Beagle dogs treated with QKLI (Wang et al., 2010). Seemingly, QKLI can lead to the degranulation of effector cells (e.g., RBL-2H3, etc.) directly (Chen et al., 2011; Cui et al., 2014). But basic secretagogues [e.g., compound 48/80 (C48/80) and substance $\mathrm{P}$, etc.] activate human mast cells degranulation through a single membrane receptor MrgprX2, whose orthologue in murine is MrgprB2 (Grimbaldeston, 2015; McNeil et al., 2015; Ali, 2016). As a rat basophilic leukemia cell line, RBL-2H3 cannot respond to C48/80 owing to the lack of these endogenous receptors (Kashem et al., 2011; Subramanian et al., 2013), which is in agreement with our observational results. Thus, the attribution of QKLI-IHR and its underlying mechanisms are far from clear. The present study indicates that QKLI can directly activate complement-derived anaphylatoxin 3 (C3), which might subsequently stimulate its effector cells (e.g., mast cells and basophils) (Ali, 2010), thus releasing histamine to cause IHRs.

\section{MATERIALS AND METHODS}

\section{Materials and Reagents}

Commercial QKLI (Batch nos. 16020204, 16020205, and 16020206) and its eight raw materials were provided by Yisheng Pharmaceutical Co., Ltd. (Ji'an, Jilin, China) and authenticated by the Quality Controller Guilan Ding according to the Chinese Pharmacopoeia (State Pharmacopoeia Committee, 2015). Four intermediate fractions in QKLI (F1, the extract of powdered buffalo horn and margaritifera concha; F2, the extract of Gardeniae Fructus; F3, the extract of Isatidis Radix; F4, the extract of Lonicerae japonicae Flos) were prepared according to the Chinese Pharmacopoeia (State Pharmacopoeia Committee, 2015). The used QKLI in this study is the mixture of three batches products. C48/80, 4-Methylumbelliferyl N-acetyl$\beta$-D-glucosaminide, propranolol, triprolidine, CV3988, and SB290157 were purchased from Sigma-Aldrich (St Louis, MO, USA). PMX53 was from TOCRIS Bioscience (Bristol, UK). Rehydragel $^{\circledR}$ aluminum adjuvant was from General Chemical (Parsippany, NJ, USA). Mouse total IgE (tIgE) ELISA kit was from Biolegend Co. (San Diego, CA, USA). Human C3a ELISA kit was from BD Biosciences (San Diego, CA, USA). Shrimp tropomyosin (ST) from Metapenaeus ensis was prepared as we previously described (Gao et al., 2017). Normal human serum was obtained from Solarbio life sciences Co. (Beijing, China).

\section{HPLC Analysis}

Commercial QKLI was assayed by a Waters HPLC system. A highresolution HPLC column (Tnature C18, $250 \mathrm{~mm} \times 4.6 \mathrm{~mm}$, $5 \mu \mathrm{m}$ ) were used. Mobile phase A was $0.1 \% \mathrm{v} / \mathrm{v}$ formic acid in water and mobile phase B was acetonitrile. The flow rate is $1 \mathrm{ml} /$ min. A gradient of mobile phase A is $0-5 \min (0 \%-2 \%), 5-8 \mathrm{~min}$ (2\%-10\%), 8-50 $\min (10 \%-30 \%)$ and $50-60 \min (30 \%-100 \%)$. The UV spectrophotometer detector was set at $235 \mathrm{~nm}$.

\section{Ethics Statement}

All the animal experiments were carried out according to the National Institutes of Health Guide for the Care and Use of Laboratory Animals and approved by the Institutional Care and Use Committee, Institute of Medicinal Plant Development of Chinese Academy of Medical Sciences. Anesthetic drugs and all other necessary measures were used to reduce animal suffering during experimental procedures.

\section{Cells and Animals}

The human mast cell line LAD2 (from Michael D. Gershon, MD, Columbia University, USA) was a gift from Prof. Renshan Sun (the Third Military Medical University, Chongqing, China). Balb/c mice (female, 18-20 g) were purchased from Vital River Experimental Animal Services (Beijing, China) and housed in an SPF laboratory under standard temperature $\left(22-24^{\circ} \mathrm{C}\right)$ and humidity (45\%-65\%) conditions with a $12 \mathrm{~h}$ light/dark cycle and standard pallet diet and water ad libitum. Primary abdominal mast cells were obtained from Balb/c mice. 


\section{Measurement of Serum tlgE}

$\mathrm{Balb} / \mathrm{c}$ mice were injected (i.p.) weekly with aluminum adjuvant (100 $\mu \mathrm{l} /$ mouse) containing QKLI (50 $\mu \mathrm{l} /$ mouse) or ST $(60 \mu \mathrm{g} /$ mouse). ST was used as a positive control allergen. The negative control mice were only treated with aluminum adjuvant. Five weeks later, the mice were euthanized and the serum was collected for the assay. Serum tIgE level was determined by using a commercial ELISA kit according to the assay protocol.

\section{$\beta$-Hexosaminidase Release Assay}

To determine the direct effect of QKLI on cell degranulation, LAD2 cells $\left(5 \times 10^{4}\right.$ cells/well $)$ or mouse peritoneal mast cells $\left(1 \times 10^{6}\right.$ cells/well $)$ were seeded in the 96 -well plates and treated with QKLI at $37^{\circ} \mathrm{C}$ for $1.5 \mathrm{~h}$. To evaluate the inhibitory effect of QKLI on C48/80-induced degranulation, the cells were pretreated with QKLI for $30 \mathrm{~min}$ followed by adding C48/80 $(10 \mu \mathrm{g} / \mathrm{ml})$ for further $1.5 \mathrm{~h}$ incubation. $30 \mu \mathrm{l}$ of the supernatant was transferred to a 96-well black flat-bottom plate accompany with $50 \mu \mathrm{l}$ of substrate solution $(0.57 \mathrm{mg} / \mathrm{ml} 4$ Methylumbelliferyl $\mathrm{N}$-acetyl- $\beta$-D-glucosaminide in the buffer contained $133 \mathrm{mM}$ sodium citrate and $133 \mathrm{mM} \mathrm{NaCl}, \mathrm{pH} 4.3$ ). The reaction proceeded at $37^{\circ} \mathrm{C}$ for $1.5 \mathrm{~h}$ and was stopped by adding stop buffer (50 mM glycine and $5 \mathrm{mM}$ EDTA-Na2, $\mathrm{pH}$ $10.5 ; 200 \mu \mathrm{l} /$ well). Fluorescence was determined with a fluorescence microplate reader at $\lambda$ ex $355 \mathrm{~nm}$ and $\lambda$ em 460 nm (Gao et al., 2017).

\section{Evans Blue Extravasation Assay}

Evans Blue extravasation in mice hind paws was measured as previously described (McNeil et al., 2015). Briefly, 15 min after induction of anesthesia (50 mg/kg of pentobarbital), mice were intraplantarly (left paw) injected with $7 \mu \mathrm{l}$ of QKLI. The right paw was injected with $7 \mu \mathrm{l}$ of NS. Five minutes later, the mice were injected (i.v.) with $100 \mu \mathrm{l}$ of $6.25 \mathrm{mg} / \mathrm{ml}$ Evans Blue. Thirty minutes later, the mice were euthanized. The paw tissues were collected and weighed. Evans Blue in the paw tissues were extracted by formamide at $60^{\circ} \mathrm{C}$ for $24 \mathrm{~h}$. The $\mathrm{OD}$ values were read at $620 \mathrm{~nm}$. The concentration of the dye in the paw tissues was calculated by the standard curve of the Evans Blue dye, and the dye content was expressed in microgram per gram of tissue.

\section{Anaphylactic Shock Assay}

Anaphylactic shock was assessed by rectal thermometry (Strait et al., 2002). To increase the severity of anaphylaxis (TenBrook et al., 2004; Khodoun et al., 2009), the mice were pretreated (i.v.) with propranolol (35 $\mu \mathrm{g} /$ mouse). Twenty minutes later, the mice were challenged (i.p.) with normal saline (NS) or QKLI (100 $\mu \mathrm{l} /$ mouse). Thirty minutes later, the rectal temperature was measured. For the antagonist experiment, CV3988 (a PAF antagonist, $0.337 \mu \mathrm{mol} / \mathrm{mouse}$ ) or triprolidine (an $\mathrm{H} 1$ antagonist, $0.64 \mu \mathrm{mol} / \mathrm{mouse}$ ) was injected (i.p.) into the mice $10 \mathrm{~min}$ before the propranolol pretreatment.

\section{Complement Activation Assay In Vitro}

The human serum (100 $\mu \mathrm{l}, 1: 500$ dilution) was mixed with $4 \mu \mathrm{l}$ of $\mathrm{CaCl}_{2}(1 \mathrm{M}), 4 \mu \mathrm{l}$ of $\mathrm{MgCl}_{2}(1 \mathrm{M})$, and $10 \mu \mathrm{l}$ of test substances, and then incubated at $37^{\circ} \mathrm{C}$. After $20 \mathrm{~min}$, the reaction was stopped using $22 \mu \mathrm{l}$ of EDTA $(0.5 \mathrm{M}, \mathrm{pH} 8.0)$ and cooling to $0^{\circ} \mathrm{C}$. Tween80 was used as a positive control (Weiszhár et al., 2012). The level of C3a in the plasma was determined using a commercial ELISA kit according to the manufacturer's instructions.

\section{Statistical Analysis}

Data are expressed as the means \pm SD from at least three independent experiments and were analyzed by a one-way analysis of variance (ANOVA). A Student $t$-test was used when only two groups were compared. A difference with a $P$ value $<0.05$ was considered statistically significant.

\section{RESULTS}

\section{Fingerprint of QKLI}

The main component profiles of QKLI were analyzed via HPLC$\mathrm{UV}$. The retention time values of the identified compounds were compared with that of the reference substances. Nine components (uridine, adenosine, guanosine, neochlorogenic acid, chlorogenic acid, caffeic acid, geniposide, baicalin, and 4,5-Di-O-caffeoylquinic acid) in QKLI were identified and their structures had also been shown (Figure 1).

\section{QKLI Fails to Induce IgE-Mediated IHR but Can Cause Non-Allergic IHR}

IgE-mediated IHRs are the most common allergic-IHRs (Strait et al., 2006). To amplify the possible T helper 2 (Th2) response, the aluminum adjuvant was used during mouse immunization. Five weeks after intraperitoneal immunization, serum tIgE level was robustly elevated by ST, while QKLI failed to increase serum tIgE (Figure 2A), indicating that QKLI-IHR is not mediated by IgE. Next, we evaluated whether QKLI could induce non-allergic IHR (NA-IHR). The local effect of QKLI on microvascular permeability was determined using the Evans Blue extravasation assay. As shown in Figure 2B, QKLI significantly induced vasopermeability increase after the first intraplantar injection, demonstrating that QKLI-IHR was non-immune-mediated.

\section{Histamine H1 Receptor Antagonist Counters QKLI Induced NA-Anaphylaxis}

Considering that QKLI was capable of causing anaphylaxis clinically (National Center for ADR Monitoring, 2008; National Center for ADR Monitoring, 2009), the effect of QKLI on mouse rectal temperature was evaluated after a single injection (i.p.). Propranolol, which does not induce shock by itself, was used for increasing the severity of QKLI-induced anaphylaxis (TenBrook et al., 2004; Khodoun et al., 2009). As shown in Figure 3, C48/80 and QKLI contributed to obvious hypothermia in propranolol-pretreated mice.

Mast cells, basophils, and macrophages contribute predominantly to the pathogenesis of anaphylaxis through their secretion of histamine or/and PAF (Strait et al., 2002; 


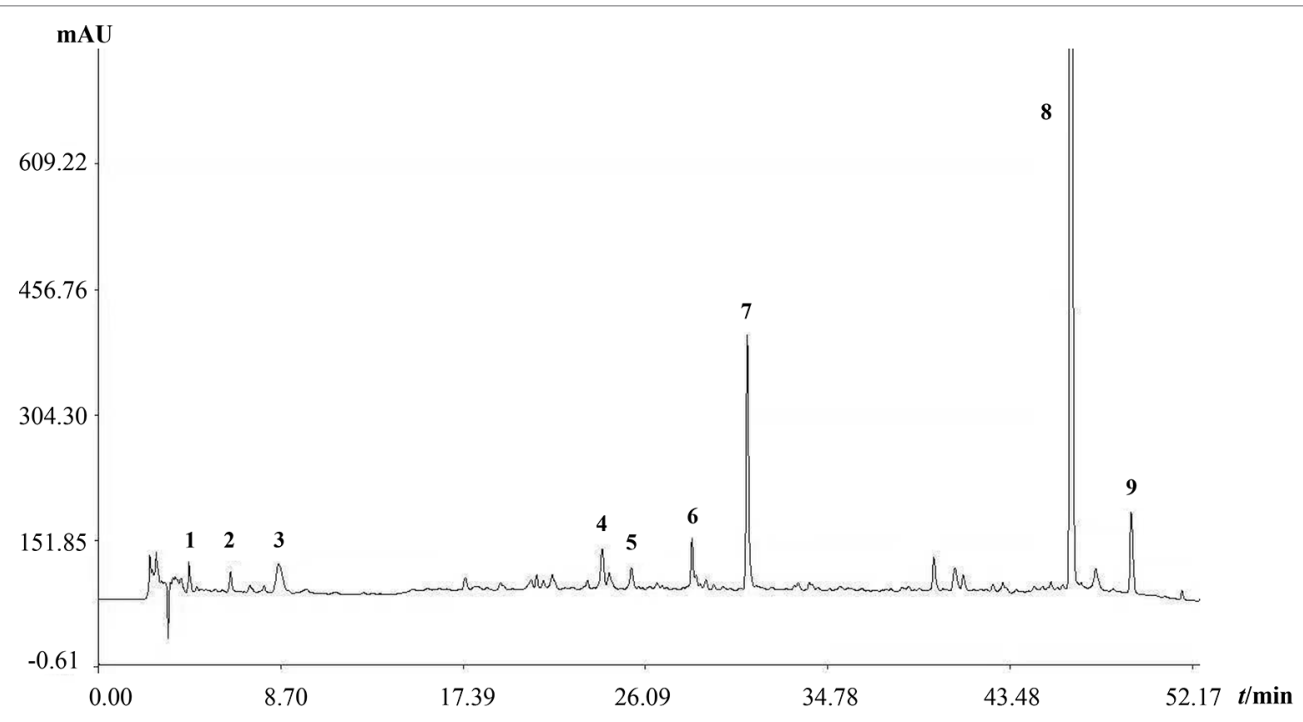<smiles>C[C@@H]1C(CO)O[C@@H](C2C=CC(=O)NC2=O)[C@@H]1C</smiles>

1. Uridine<smiles>Nc1ncnc2c1ncn2[C@@H]1O[C@H](CO)[C@@H](O)[C@H]1O</smiles>

2. Adenosine<smiles>Nc1nc2c(ncn2[C@@H]2O[C@H](CO)[C@@H](O)[C@H]2O)c(=O)[nH]1</smiles>

3. Guanosine<smiles>O=C(/C=C/c1ccc(O)c(O)c1)O[C@@H]1C[C@](O)(C(=O)O)C[C@H](O)[C@H]1O</smiles>

4. Neochlorogenic acid<smiles>O=C(/C=C/c1ccc(O)c(O)c1)O[C@@H]1C[C@@](O)(C(=O)O)C[C@H](O)[C@H]1O</smiles>

5. Chlorogenic acid<smiles>O=C(O)/C=C/c1ccc(O)c(O)c1</smiles>

6. Caffeic acid<smiles>COC(=O)C1=CO[C@@H](O[C@@H]2O[C@H](CO)[C@@H](O)[C@H](O)[C@H]2O)C2C(CO)=CCC12</smiles>

7. Geniposide<smiles>CC1C(C(=O)O)OC(Cc2cc3oc(-c4ccccc4)cc(=O)c3c(O)c2O)C(O)[C@@H]1O</smiles>

8. Baicalin<smiles>O=C(/C=C/c1ccc(O)c(O)c1)O[C@H]1[C@@H](O)C[C@@](O)(C(=O)O)C[C@H]1OC(=O)/C=C/c1ccc(O)c(O)c1</smiles>

9. 4,5-Di-O-caffeoylquinic acid

FIGURE 1 | Chromatogram fingerprint of Qing-Kai-Ling Injection. 


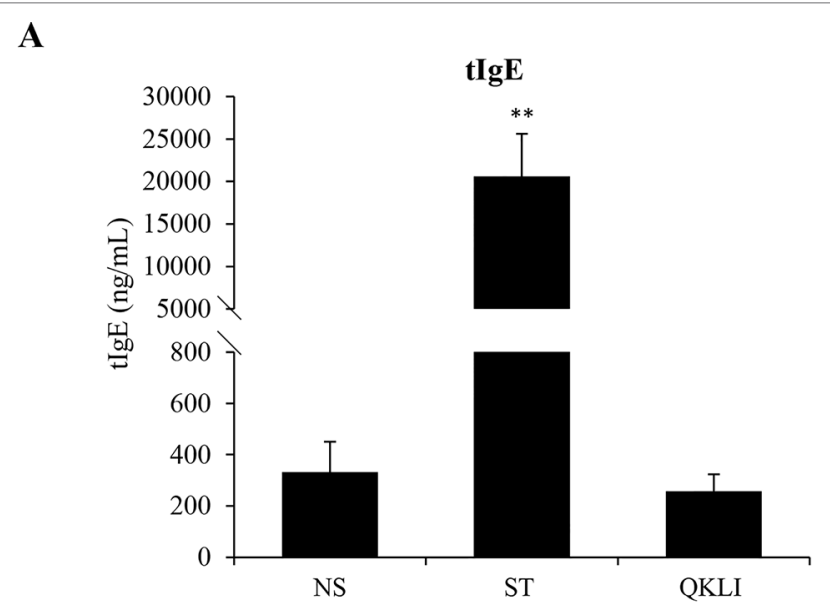

B

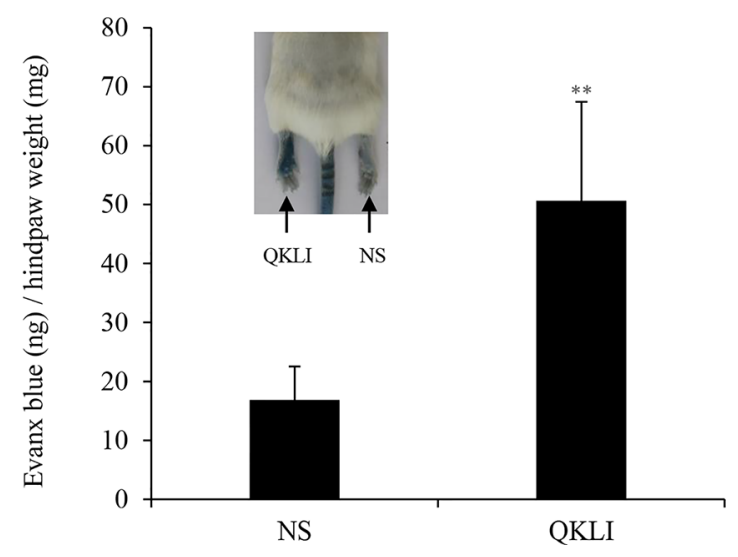

FIGURE 2 | QKLI fails to induce IgE-mediated IHRs but can cause NA-IHRs. (A) QKLI failed to elevate mouse serum tlgE. Mice were injected weekly (i.p.) with aluminum adjuvant (100 $\mu \mathrm{l} /$ mouse) containing QKLI (50 $\mu \mathrm{l} /$ mouse) or ST (60 $\mu \mathrm{g} /$ mouse). Five weeks later, the serum tlgE level was determined using a commercial ELISA kit. ${ }^{* \star} P<0.01$ vs. NS. (B) QKLI induced vasopermeability increase after the first intraplantar injection. Fifteen minutes after induction of anesthesia (50 mg/kg of pentobarbital), mice were intraplantarly (left paw) injected with $7 \mu \mathrm{l}$ of QKLI. The right paw was injected with $7 \mu \mathrm{l}$ of NS. Five minutes later, the mice were injected (i.v.) with $100 \mu \mathrm{l}$ of $6.25 \mathrm{mg} / \mathrm{ml}$ Evans Blue. Thirty minutes later, the mice were euthanized. The paw tissues were collected and weighed. Evans Blue in the paw tissues were extracted by formamide at $60^{\circ} \mathrm{C}$ for $24 \mathrm{~h}$. The OD values were read at $620 \mathrm{~nm}$. The concentration of the dye in the paw tissues was calculated by the standard curve of the Evans Blue dye, and the dye content was expressed in microgram per gram of tissue. ${ }^{\star \star} P<0.01$ vs. NS. QKLI, Qing-Kai-Ling Injection; IHR, immediate hypersensitivity reaction; NA-IHR, non-allergic IHR; tlgE, total IgE; NS, normal saline.

Tsujimura et al., 2008). Thus, we used a PAF antagonist CV3988 and a histamine $\mathrm{H} 1$ receptor antagonist triprolidine for blocking QKLI-caused hypothermia. As a result, QKLI-induced anaphylaxis was not affected by CV3988 (data not shown), but significantly countered by triprolidine (Figure 3), indicating that histamine, rather than PAF, was the principal effector in QKLIcaused NA-anaphylaxis.

\section{QKLI Triggers NA-IHR by Activating Anaphylatoxin C3}

Given that histamine is mainly released by the activated mast cells (Borriello et al., 2017), we firstly determined whether QKLI could directly promote mast cell degranulation. As shown in Figure 4A, $10 \mu \mathrm{g} / \mathrm{ml}$ of $\mathrm{C} 48 / 80$ evoked a markedly $\beta$ hexosaminidase release in both human LAD2 cells and mouse peritoneal mast cells, while QKLI could not induce mast cell degranulation. And not only that, it can dampen C48/80induced degranulation concentration-dependently in LAD2 cells (Figure 4B) without cytotoxicity (data not shown), showing a potent mast cell stabilization effect.

To our knowledge, anaphylatoxin C3a or C5a can activate mast cells to secrete histamine (Johnson et al., 1975). Perhaps the QKLI-IHR is mediated by the activated complement. Accordingly, we used a C3a antagonist (SB290157) and a C5a antagonist (PMX53) to antagonize QKLI-induced vascular permeability increase. The result showed that SB290157, but not PMX53, significantly attenuated QKLI-induced Evans Blue extravasation (Figure 4C). Consistently, in an anaphylactic shock assay, QKLI-induced anaphylaxis could also be countered by SB290157 (Figure 4D), showing QKLI-caused NA-IHR was attributed to $\mathrm{C} 3 \mathrm{a}$, rather than $\mathrm{C} 5 \mathrm{a}$.

\section{Isatidis Radix Is Responsible for QKLI-IHR}

To identify the main constituent(s) causing QKLI-IHR, all intermediate fractions in QKLI, including four extracts (F1-F4) and three compounds (cholic acid, hyodeoxycholic acid, and baicalin), were ready according to the Chinese Pharmacopoeia (State Pharmacopoeia Committee, 2015), and respectively evaluated their potential ability to cause IHRs. As a result, at their equivalent concentrations in QKLI, only F3 (Isatidis Radix) markedly caused Evans Blue leakage into the paw after the first intraplantar injection (Figure 5A), and other fractions could not increase vasopermeability (data not shown). To confirm the above finding, QKLI without F3 (F3-free QKLI) and QKLI (self-QKLI) were prepared (235 mg F1, $275 \mathrm{mg} \mathrm{F} 2,3.02 \mathrm{~g} \mathrm{~F}$, $530 \mathrm{mg} \mathrm{F} 4,325 \mathrm{mg}$ cholic acid, $375 \mathrm{mg}$ hyodeoxycholic acid, and $500 \mathrm{mg}$ baicalin were dissolved in water for injection to make 100 $\mathrm{ml}, \mathrm{pH}$ 7.4). In agreement with commercial QKLI, self-QKLI, rather than F3-free QKLI, also potently induced hindpaw Evans Blue extravasation (Figure 5B). These results indicated that Isatidis Radix was the crime culprit of QKLI-IHR. This finding, together with complement activation mechanism of QKLI-IHR, urged us to use a C3a antagonist SB290157 for the next experiment. Not surprisingly, SB290157 significantly weakened F3-caused Evans Blue leakage into the paw (Figure 5C). In vitro results also showed that QKLI and F3 directly activated C3 in a concentration-dependent manner (Figure 5D) with the half effective concentration $\left(\mathrm{EC}_{50}\right)$ values of $0.69 \%$ and $218.6 \mu \mathrm{g} / \mathrm{ml}$, respectively.

To search for the definite ingredients for QKLI-IHR, we also tested nine availably characteristic compounds of Isatidis Radix, including indirubin, epigoitrin, DL-goitrin, 2-(1H-indol-3-yl) acetonitrile, indigo, chlorogenic acid, (1-methoxy-1H-indol-3- 

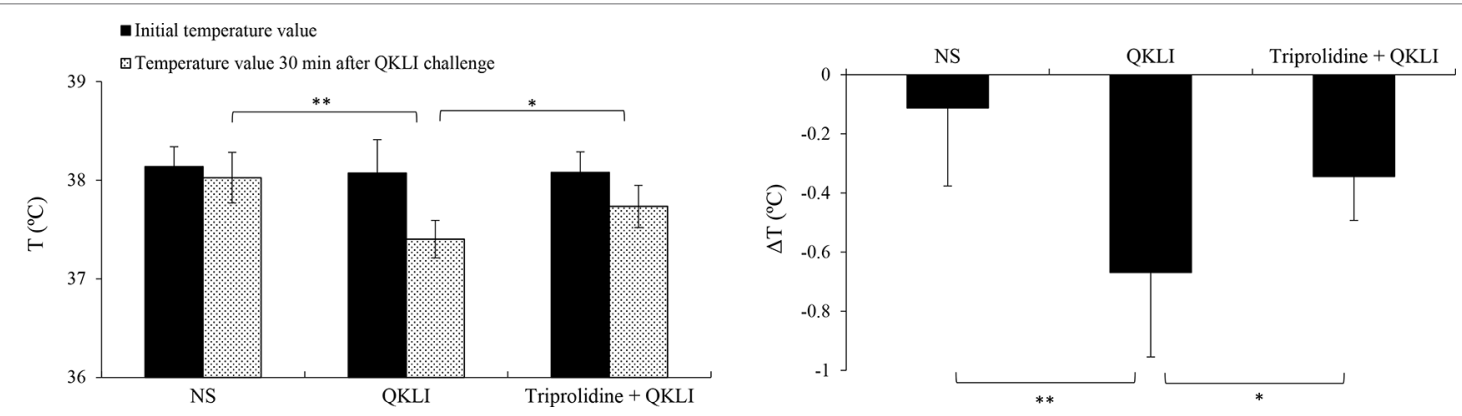

FIGURE 3 | QKLI-induced hypothermia can be countered by triprolidine in propranolol-pretreated mice $(n=8)$. Triprolidine $(0.64 \mu \mathrm{mol} / \mathrm{mouse})$ or NS was injected (i.p.) into the mice. Ten minutes later, the mice were pretreated (i.v.) with propranolol ( $35 \mu \mathrm{g} / \mathrm{mouse}$ ). Twenty minutes later, the mice were injected (i.p.) with NS or QKLI (100 $\mu$ l/mouse). The rectal temperature was measured 30 min later. ${ }^{*} P<0.05$ and ${ }^{* *} P<0.01$. QKLI, Qing-Kai-Ling Injection; NS, normal saline.

yl) acetonitrile, caffeic acid, and geniposide. Regrettably, none of them induced vasopermeability increase at a dose of $10 \mathrm{mM}$ which is far higher than their equivalent concentrations in QKLI (data not shown), indicating that the 9 compounds are not the material basis of QKLI-IHR.

\section{DISCUSSION}

IHRs can be divided into allergic- and as non-allergic-mediated (Johansson et al., 2001). Most of QKLI-IHRs are likely to be nonallergic owing to the fact that QKLI-IHRs commonly occurred after the first treatment clinically (Xiang, 2010), but allergicmediated IHRs cannot be ruled out yet. There are two pathways that can lead to allergic-mediated IHRs: the IgE-mediated classic pathway and the IgG-mediated alternative pathway (Strait et al., 2002). Although the kinetics and clinical features of these two types are generally similar, IgE is easier to cause allergy because considerably more antibody and antigen are required to induce IgG-mediated allergy (Strait et al., 2006). Thus, the potentiality of IgE-mediated allergy by QKLI was firstly evaluated. To amplify the possible Th2 response, an aluminum adjuvant was used during mouse immunization. Serum tIgE level was measured after 5 weeks, and during this period the $\operatorname{tgE}$ concentration should be peak and stable (Gao et al., 2018). By contrast to ST, QKLI did not increase serum tIgE under our experimental conditions (Figure 2A), suggesting that it seems very unlikely to induce allergy by QKLI.

Consistent with clinical practice, QKLI can significantly contribute to NA-IHRs in both local (increase of microvascular permeability, Figure 2B) and systemic (induction of hypothermia, Figure 3) models. A histamine H1 receptor antagonist triprolidine can counter QKLI-induced NA-IHRs (Figure 3). Histamine is primarily secreted by mast cells (Borriello et al., 2017), suggesting that QKLI-IHRs might be mast cell-dependent. Mast cells can be activated by basic secretagogues (e.g., C48/80 or substance P) through a single receptor Mas-related gene receptor MrgprX2 (McNeil et al., 2015), which raises the question whether that QKLI possesses the characteristics of basic secretagogues. For the reason, two cells (human mast cell line LAD2 and mouse peritoneal mast cells) with the specific receptor MrgprX2 or MrgprB2 were used (Subramanian et al., 2013). As a result, QKLI could not induce two cells degranulation (Figure 4A). In C48/80-simulated LAD2 cells, QKLI even dampened $\beta$-hexosaminidase release (Figure 4B), indicating that QKLI induces NA-IHR via an indirect rather than direct effect on mast cells.

The complement-derived anaphylatoxins C3a and C5a can activate mast cells by binding to their respective receptors $\mathrm{C} 3 \mathrm{aR}$ and $\mathrm{C} 5 \mathrm{aR}$ and consequently lead to degranulation and histamine secretion (Ali, 2010). QKLI-IHR was countered by a C3a antagonist SB290157 (Figures 4C, D), rather than C5a antagonist (PMX53), demonstrating that QKLI might directly activate complement C3 in circulatory system. Indeed, QKLI directly activated $\mathrm{C} 3$ in human serum in vitro with an $\mathrm{EC}_{50}$ value of $0.69 \%$ (Figure 5D). According to the Chinese Pharmacopoeia (State Pharmacopoeia Committee, 2015), QKLI consists of seven fractions including four extracts and three compounds, of which F3 (the extract of Isatidis Radix), rather than other six fractions, potently induced Evans Blue extravasation in mouse hindpaw. This effect was disappeared in F3-free QKLI (Figures 5A, B) and also could be countered by the C3a antagonist (Figure 5C), indicating that the crime culprit for QKLI-IHR is Isatidis Radix, a non-ANP-derived material. Some components from Isatidis Radix, including baicalin and the other two botanical drugs (Gardeniae Fructus and Lonicerae japonicae Flos), were identified by HPLC (Figure 1). Next, we determined the effects of the available components from Isatidis Radix on the vascular permeability. Regrettably, the main ingredient(s) responsible for the QKLI-IHR was not found out. Accordingly, further chemical research is needed to obtain more new components of Isatidis Radix for identifying its pseudoallergic substances. In fact, QKLIIHR is complement activation-related pseudoallergy (CARPA) (Szebeni, 2005), which was also commonly triggered by many chemical intravenous preparations, such as intravenous iron (Hempel et al., 2017), radiocontrast agents (Szebeni, 2001), etc. Obviously, as an extract of ANP, QKL induces an emerging CARPA 
A

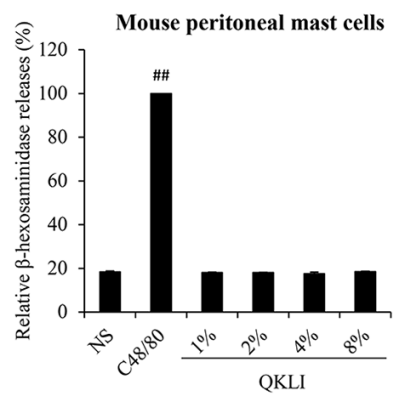

C
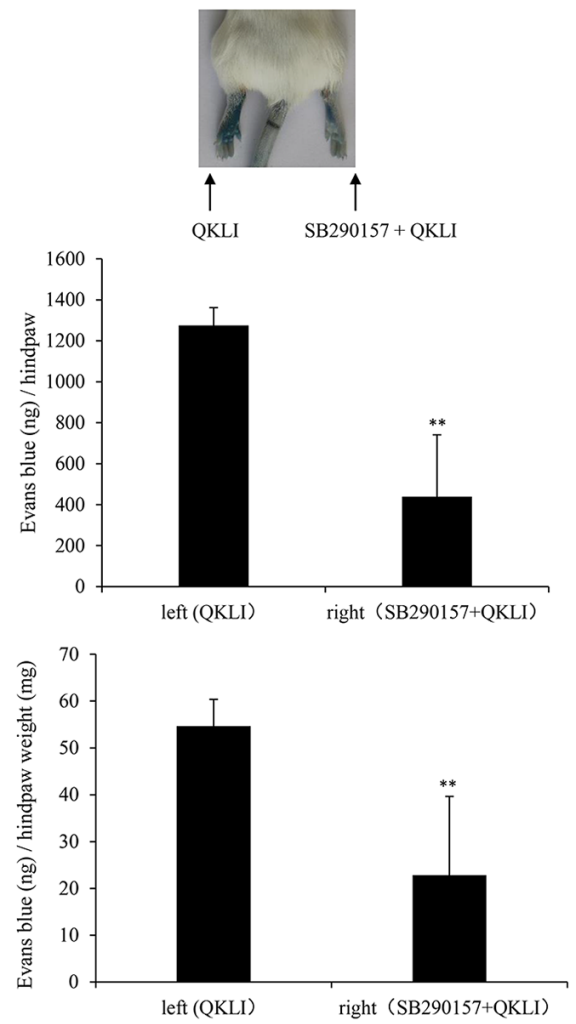

D

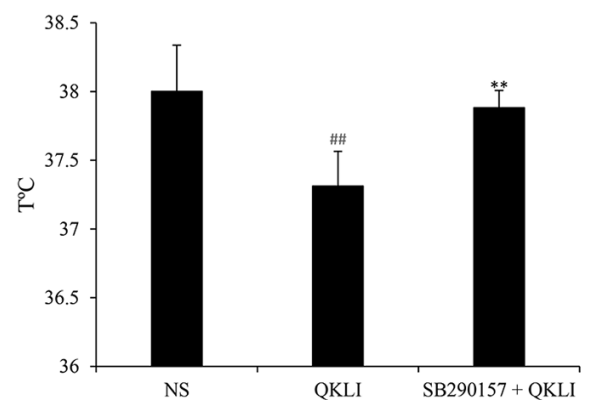

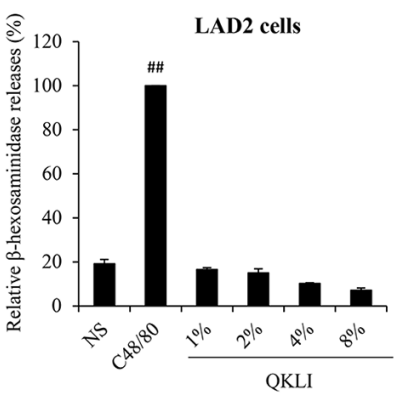

$\mathrm{C} 48 / 80(10 \mu \mathrm{g} / \mathrm{mL})$ -
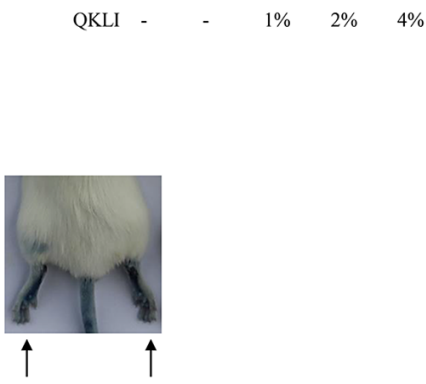

QKLI $\quad$ PMX53+ QKLI
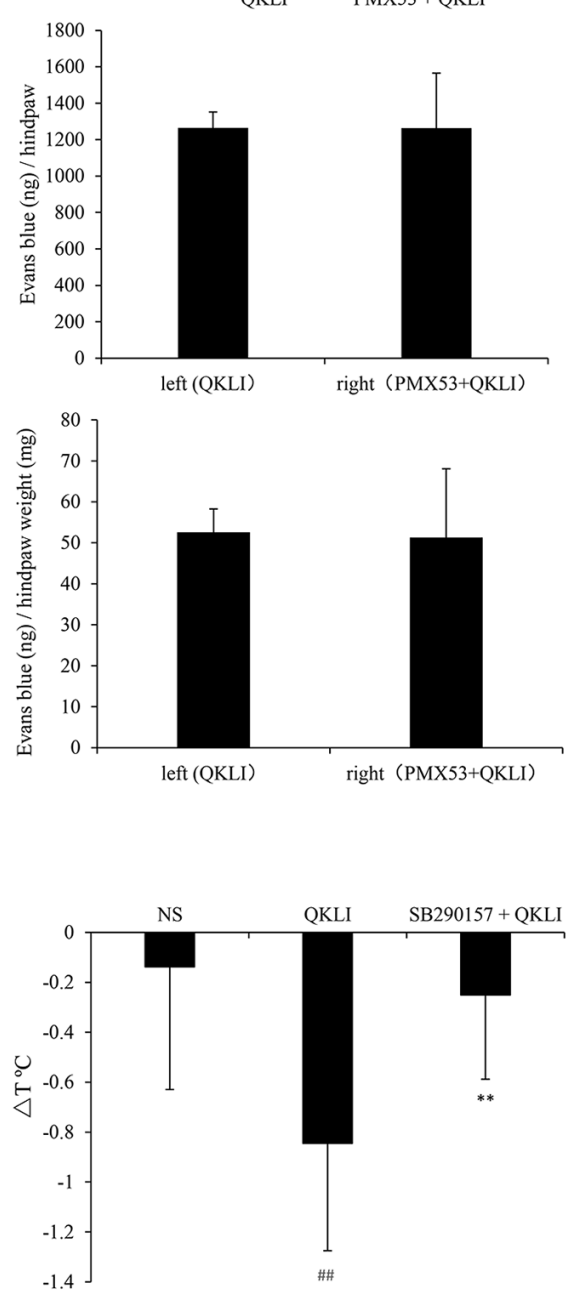

FIGURE 4 Continued 
FIGURE 4 | QKLI-induced NA-IHRs is mediated by C3a. (A) Effect of QKLI on the $\beta$-hexosaminidase release in mouse peritoneal mast cells and LAD2 cells. Cells were treated with QKLI at the indicated concentrations. Supernatant $\beta$-hexosaminidase level was determined $1.5 \mathrm{~h}$ later. C48/80 (10 $\mu \mathrm{g} / \mathrm{ml})$ was used as a positive control. ${ }^{\# \#} P<0.01$ vs. NS group. (B) QKLI decreased C48/80-induced $\beta$-hexosaminidase release in LAD2 cells. Cells were pretreated with QKLI for 30 min followed

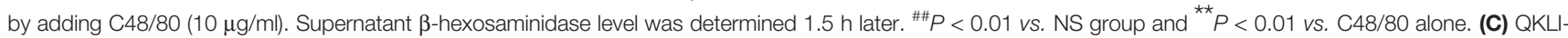
induced Evans Blue extravasation was attenuated by SB290157 but not PMX53 $(n=5)$. Fifteen minutes after induction of anesthesia (50 mg/kg of pentobarbital), mice were intraplantarly injected with $15 \mu$ l of SB290157 (2 mg/ml) or PMX53 $(1 \mathrm{mg} / \mathrm{ml})$ or NS. Fifteen minutes later, the mice were intravenously injected with $100 \mu$ l of $6.25 \mathrm{mg} / \mathrm{ml}$ Evans Blue. Five minutes later, $7 \mu \mathrm{l}$ of QKLI was administered by intraplantar injection in the hindpaws. Thirty minutes later, the mice were euthanized. The paw tissues were collected and weighed. Evans Blue was extracted by formamide at $60^{\circ} \mathrm{C}$ for $24 \mathrm{~h}$. The OD values were read at $620 \mathrm{~nm}$. The concentration of the dye in the paw tissues was calculated by the standard curve of the Evans Blue dye, and the dye content was expressed in microgram per gram of tissue. ${ }^{\star \star} P<$ 0.01 vs. QKLI alone. (D) SB290157 could block QKLI-induced anaphylaxis $(n=8)$. The mice were pretreated with propranolol (intravenously, i.v., $35 \mu \mathrm{g} / \mathrm{mouse}) 10$ min after intraperitoneally injected with SB290157 (a C3a antagonist, $30 \mathrm{mg} / \mathrm{kg}$ ). Twenty minutes later, the mice were intraperitoneally challenged with QKLI (100 $\mu$ l/ mouse). Thirty minutes later, the rectal temperature was measured. ${ }^{\# \#} P<0.01$ vs. NS and ${ }^{\star \star} P<0.01$ vs. QKLI alone. QKLI, Qing-Kai-Ling Injection; NA-IHR, nonallergic IHR; NS, normal saline.

A

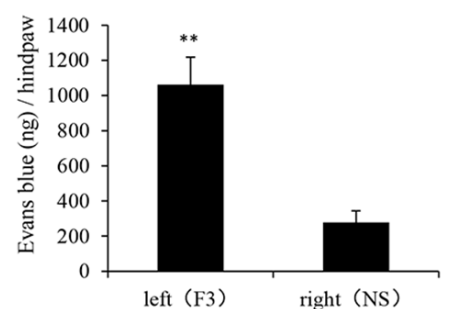

C

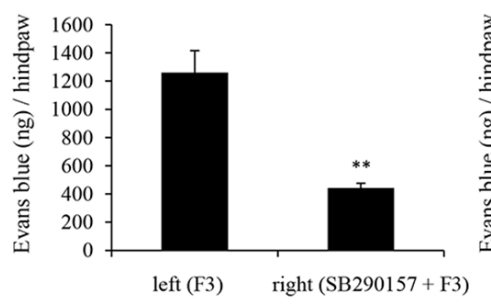

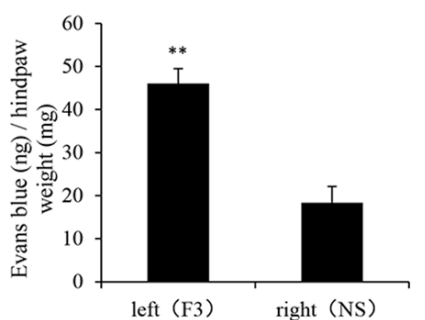

left (F3)

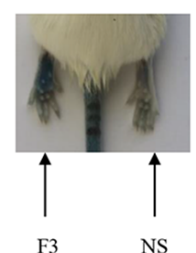

NS
B

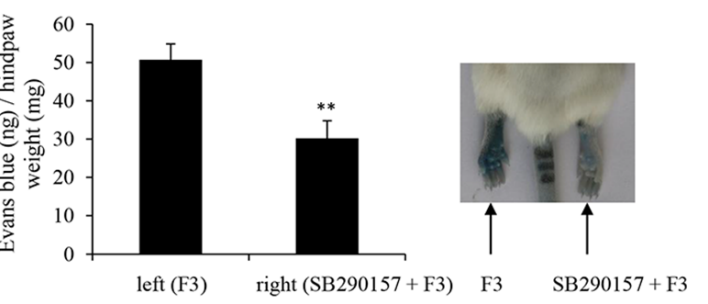

D

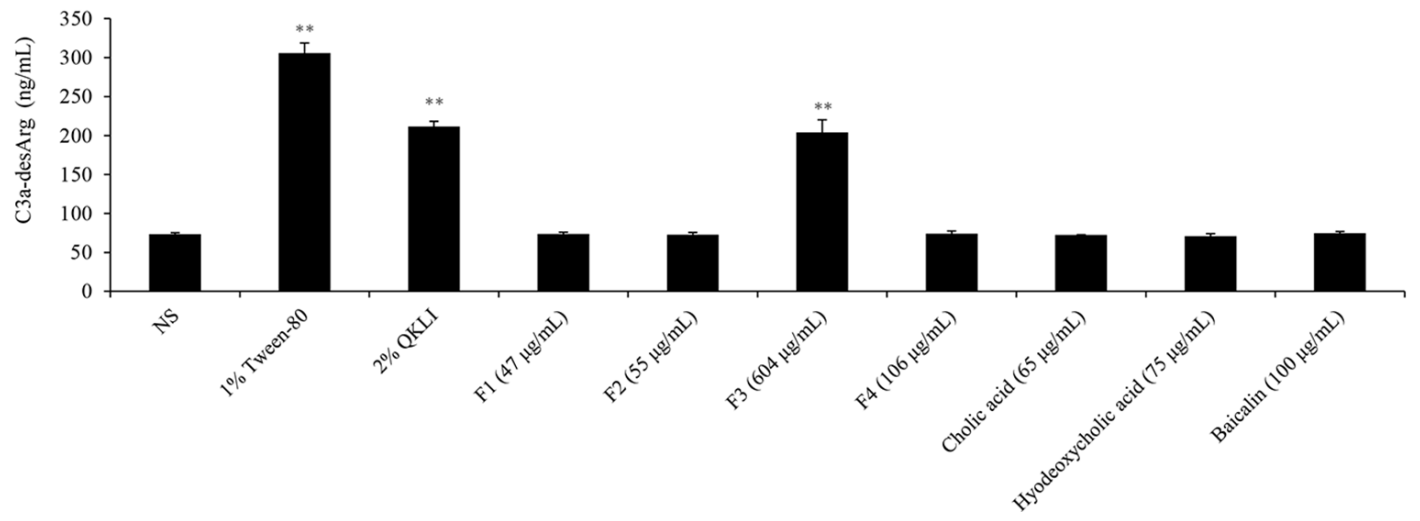

FIGURE 5 | Isatidis Radix is responsible for QKLI-IHR. (A) F3 increased vasopermeability after the first intraplantar injection $(n=5)$. Fifteen minutes after induction of anesthesia ( $50 \mathrm{mg} / \mathrm{kg}$ of pentobarbital), mice were intraplantarly (left paw) injected with $7 \mu \mathrm{l}$ of F3 $(30.2 \mathrm{mg} / \mathrm{mll}$ ). The right paws were injected with $7 \mu \mathrm{l}$ of NS. Five minutes later, the mice were injected (i.v.) with $100 \mu \mathrm{l}$ of $6.25 \mathrm{mg} / \mathrm{ml}$ Evans Blue. Thirty minutes later, the mice were euthanized. The paw tissues were collected and weighed. Evans Blue was extracted by formamide at $60^{\circ} \mathrm{C}$ for $24 \mathrm{~h}$. The OD values were read at $620 \mathrm{~nm}$. The concentration of the dye in the paw tissues was calculated by the standard curve of the Evans Blue dye, and the dye content was expressed in microgram per gram of tissue. ${ }^{\star *} P<0.01 \mathrm{vs}$. NS. (B) Representative image of Evans Blue extravasation of mouse paw induced by F3-free QKLI and self-QKLI. (C) F3-induced Evans Blue extravasation was attenuated by SB290157 $(n=5) .{ }^{* *} P<0.01$ vs. F3 alone. (D) QKLI and F3 directly activated C3 in vitro. The plasma was treated with test substances at the indicated concentrations and C3a-desArg level was determined by a commercial ELISA kit. Tween-80 was used as a positive control. ${ }^{\star \star} P<0.01$ vs. NS. 
which resulted from the addition of Isatidis Radix and the change of traditional drug-delivery way (p.o.). In the current situation, the pseudoallergic potency of Isatidis Radix should be emphatically monitored because it determines the intensity of QKLI-IHR.

In conclusion, this is the first study to show that QKLI-IHR is CARPA, rather than an IgE-mediated allergy. QKLI causes C3 activation, and might consequently activate mast cells to release histamine, which is a principal effector of its NA-IHR. In the seven fractions of QKLI, Isatidis Radix is primarily responsible for QKLI-IHR. Further explorations are required to identify the basis material associated with Isatidis Radixinduced NA-IHR. Our study suggests a potential therapeutic strategy for the prophylaxis and treatment of QKLI-IHR.

\section{DATA AVAILABILITY STATEMENT}

The raw data supporting the conclusions of this article will be made available by the authors, without undue reservation, to any qualified researcher.

\section{REFERENCES}

Ali, H. (2010). Regulation of human mast cell and basophil function by anaphylatoxins C3a and C5a. Immunol. Lett. 128, 36-45. doi: 10.1016/ j.imlet.2009.10.007

Ali, H. (2016). Mas-related G protein coupled receptor-X2: a potential new target for modulating mast cell-mediated allergic and inflammatory diseases. $J$. Immunobiol. 1, 115. doi: 10.4172/2476-1966.1000115

Aun, M. V., Kalil, J., and Giavina-Bianchi, P. (2017). Drug-induced anaphylaxis. Immunol. Allergy Clin. North Am. 37, 629-641. doi: 10.1016/j.iac.2017.06.002

Borriello, F., Iannone, R., and Marone, G. (2017). Histamine release from mast cells and basophils. Handb. Exp. Pharmacol. 241, 121-139. doi: 10.1007/ 164_2017_18

Chen, L. J., Liao, G. P., Wang, Y., He, S., and Zhang, Z. Y. (2011). Effect of Qingkailing injection (QKLI) on complement and RBL-2H3 cells in vitro. Chin. J. Chin. Mater. Med. 36, 1884-1888. doi: 10.1007/s10570-010-9464-0

Cui, H. Y., Yi, Y., Li, C. Y., Zhang, Y. S., Zhao, Y., Li, G. Q., et al. (2014). Experimental study on pseudoallergic reaction of Qingkailing injection. Chin. J. Chin. Mater. Med. 39, 511-514. doi: 10.4268/cjcmm20140329

Fu, W. J., Lei, T., Yin, Z., Pan, J. H., Chai, Y. S., Xu, X. Y., et al. (2017). Antiatherosclerosis and cardio-protective effects of the Angong Niuhuang Pill on a high fat and vitamin D3 induced rodent model of atherosclerosis. J. Ethnopharmacol. 195, 118-126. doi: 10.1016/j.jep.2016.11.015

Gao, Y., Hou, R., Fei, Q., Fang, L., Han, Y., Cai, R., et al. (2017). The three-herb formula Shuang-Huang-Lian stabilizes mast cells through activation of mitochondrial calcium uniporter. Sci. Rep. 7, 38736. doi: 10.1038/srep38736

Gao, Y., Hou, R., Han, Y., Fei, Q., Cai, R., and Qi, Y. (2018). Shuang-Huang-Lian injection induces an immediate hypersensitivity reaction via C5a but not IgE. Sci. Rep. 8, 3572. doi: 10.1038/s41598-018-21843-7

Gao, X., Qin, L., Zhang, Z., Zhao, H., Zhou, W., Xie, Z., et al. (2018). Deciphering biochemical basis of Qingkailing injection-induced anaphylaxis in a rat model by time-dependent metabolomic profiling based on metabolite polarityoriented analysis. J. Ethnopharmacol. 225, 287-296. doi: 10.1016/ j.jep.2018.07.013

Grimbaldeston, M. A. (2015). Mast cell-MrgprB2: sensing secretagogues or a means to overreact? Immunol. Cell Biol. 93, 221-223. doi: 10.1038/icb.2015.10

Hempel, J. C., Poppelaars, F., Gaya da Costa, M., Franssen, C. F., de Vlaam, T. P., Daha, M. R., et al. (2017). Distinct in vitro complement activation by various intravenous iron preparations. Am. J. Nephrol. 45, 49-59. doi: 10.1159/000451060

Johansson, S. G., Hourihane, J. O., Bousquet, J., Bruijnzeel-Koomen, C., Dreborg, S., Haahtela, T., et al. (2001). A revised nomenclature for allergy. an EAACI position statement from the EAACI nomenclature task force. Allergy 56, 813-824. doi: 10.1111/j.1398-9995.2001.00002.x-i1

\section{AUTHOR CONTRIBUTIONS}

YG and YQ wrote the manuscript. YG, RQ, XZ, XX, YH, QF, and XW performed the experiments. RC analyzed the raw data. GS and YQ designed the study and reviewed the manuscript. All authors read and approved the final version of the manuscript.

\section{FUNDING}

This work was supported by the National S\&T Major Project and Scientific Researchers Aiding Enterprise Item from the Ministry of Science and Technology of the People's Republic of China (No. 2015ZX09501004-001-003), the CAMS Innovation Fund for Medical Sciences (2016-I2M-3-015), the National Natural Science Foundation of China (Nos. 81601385 and 81873066), and the Drug Innovation Major Project (No. 2018ZX09711001-009-012).

Johansson, S. G., Bieber, T., Dahl, R., Friedmann, P. S., Lanier, B. Q., Lockey, R. F., et al. (2004). Revised nomenclature for allergy for global use: report of the nomenclature review committee of the world allergy organization, october 2003. J. Allergy Clin. Immunol. 113, 832-836. doi: 10.1016/j.jaci.2003.12.591

Johnson, A. R., Hugli, T. E., and Müller-Eberhard, H. J. (1975). Release of histamine from rat mast cells by the complement peptides C3a and C5a. Immunology 28, 1067-1080.

Kashem, S. W., Subramanian, H., Collington, S. J., Magotti, P., Lambris, J. D., and Ali, H. (2011). G protein coupled receptor specificity for C3a and compound 48/80-induced degranulation in human mast cells: roles of Mas-related genes MrgX1 and MrgX2. Eur. J. Pharmacol. 668, 299-304. doi: 10.1016/ j.ejphar.2011.06.027

Khodoun, M., Strait, R., Orekov, T., Hogan, S., Karasuyama, H., Herbert, D. R., et al. (2009). Peanuts can contribute to anaphylactic shock by activating complement. J. Allergy Clin. Immunol. 123, 342-351. doi: 10.1016/ j.jaci.2008.11.004

Li, B. Q., Dong, X., Yang, G. Q., Fang, S. H., Gao, J. Y., Zhang, J. X., et al. (2010). Role of chlorogenic acid in the toxicity induced by Chinese herbal injections. Drug Chem. Toxicol. 33, 415-420. doi: 10.3109/01480540903580055

Liu, J., Lu, Y. F., Wu, Q., Goyer, R. A., and Waalkes, M. P. (2008a). Mineral arsenicals in traditional medicines: orpiment, realgar, and arsenolite. $J$. Pharmacol. Exp. Ther. 326, 363-368. doi: 10.1124/jpet.108.139543

Liu, J., Shi, J. Z., Yu, L. M., Goyer, R. A., and Waalkes, M. P. (2008b). Mercury in traditional medicines: is cinnabar toxicologically similar to common mercurials? Exp. Biol. Med. (Maywood) 233, 810-817. doi: 10.3181/0712MR-336

McNeil, B. D., Pundir, P., Meeker, S., Han, L., Undem, B. J., Kulka, M., et al. (2015). Identification of a mast-cell-specific receptor crucial for pseudo-allergic drug reactions. Nature 519, 237-241. doi: 10.1038/nature14022

National Center for ADR Monitoring. (2008). Notification of adverse drug reactions (No. 1). Bimolane (tablet and capsule) may cause leukemia during the treatment of psoriasis; Zhuang-Gu-Guan-Jie pills and hepatic lesion; QingKai-Ling injection and allergy; Shuang-Huang-Lian injection and allergy. http://www.cdr-adr.org.cn/xxtb_255/ypblfyxxtb/200806/t20080626_2815. html

National Center for ADR Monitoring. (2009). Notification of adverse drug reactions (No. 21). Alarm of the serious adverse reactions induced by intravenous cefoperazone sodium, sulbactam sodium and Qing-Kai-Ling. http://www.cdr-adr.org.cn/xxtb_255/ypblfyxxtb/200904/t20090422_2838. html

State Pharmacopoeia Committee. (2015). Chinese Pharmacopoeia (Chemical Industry Press: Beijing), 1529-1531. 
Strait, R. T., Morris, S. C., Yang, M., Qu, X. W., and Finkelman, F. D. (2002). Pathways of anaphylaxis in the mouse. J. Allergy Clin. Immunol. 109, 658-668. doi: 10.1067/mai.2002.123302

Strait, R. T., Morris, S. C., and Finkelman, F. D. (2006). IgG-blocking antibodies inhibit IgE-mediated anaphylaxis in vivo through both antigen interception and Fc gamma RIIb cross-linking. J. Clin. Invest. 116, 833-841. doi: 10.1172/ JCI25575

Subramanian, H., Gupta, K., Lee, D., Bayir, A. K., Ahn, H., and Ali, H. (2013). $\beta$ Defensins activate human mast cells via Mas-related gene X2. J. Immunol. 191, 345-352. doi: 10.4049/jimmunol.1300023

Szebeni, J. (2001). Complement activation-related pseudoallergy caused by liposomes, micellar carriers of intravenous drugs, and radiocontrast agents. Crit. Rev. Ther. Drug Carrier. Syst. 18, 567-606. doi: 10.1007/1-4020-8056-5_17

Szebeni, J. (2005). Complement activation-related pseudoallergy: a new class of drug-induced acute immune toxicity. Toxicology 216, 106-121. doi: 10.1016/ j.tox.2005.07.023

TenBrook, J. A.Jr., Wolf, M. P., Hoffman, S. N., Rosenwasser, L. J., Konstam, M. A., Salem, D. N., et al. (2004). Should beta-blockers be given to patients with heart disease and peanut-induced anaphylaxis? A decision analysis. J. Allergy Clin. Immunol. 113, 977-982. doi: 10.1016/j.jaci.2004.02.043

Topic Study Group in Beijing College of Traditional Chinese Medicine. (1975). The study of novel dosage form of An Gong Niu Huang Wan. New J. Med. 4, 12-13. doi: 10.13288/j.11-2166/r.1975.08.002

Tsujimura, Y., Obata, K., Mukai, K., Shindou, H., Yoshida, M., Nishikado, H., et al. (2008). Basophils play a pivotal role in immunoglobulin-G-mediated but not immunoglobulin-E-mediated systemic anaphylaxis. Immunity 28, 581-589. doi: 10.1016/j.immuni.2008.02.008

Wang, Z. G., Wang, D. Q., Wu, Z. E., Li, L. D., and Wei, F. (2010). Experimental study on the anaphylactoid reaction induced by Qingkailing injections on the Beagle dogs. J. Tradit. Chin. Med. 51, 362-364. doi: 10.13288/j.11-2166/r.2010.04.043
Weiszhár, Z., Czúcz, J., Révész, C., Rosivall, L., Szebeni, J., and Rozsnyay, Z. (2012) Complement activation by polyethoxylated pharmaceutical surfactants: Cremophor-EL, Tween-80 and Tween-20. Eur. J. Pharm. Sci. 45, 492-498. doi: 10.1016/j.ejps.2011.09.016

Xiang, H. Y. (2010). Discussion of the adverse reaction and rational clinical use of Qingkailing injection. Chin. J. Exp. Tradit. Med. Form 16, 199-200. doi: 10.3969/j.issn.1005-9903.2010.15.060

Zhang, Z., Qin, L., Peng, L., Zhang, Q., Wang, Q., Lu, Z., et al. (2016). Pharmacokinetic-pharmacodynamic modeling to study the antipyretic effect of qingkailing injection on pyrexia model rats. Molecules 21, 317. doi: 10.3390/ molecules21030317

Zhao, Y. B., Xiao, Y., and Xie, Y. M. (2011). Clinical study on changes of serum levels of immunoglobulin and cytokines in anaphylaxis patients induced by Qingkailing injection. Chin. J. Chin. Mater. Med. 36, 1382-1385. doi: 10.1007/ s10008-010-1224-4

Zhong, Q., Lin, K., and Wen, J. (2012). Document analysis of Qingkailing injection-induced adverse reaction (313 cases). Clin. J. Tradit. Chin. Med. 24, 723-725. doi: 10.16448/j.cjtcm.2012.08.043

Conflict of Interest: The authors declare that the research was conducted in the absence of any commercial or financial relationships that could be construed as a potential conflict of interest.

Copyright (c) 2020 Gao, Qi, Zhang, Xu, Han, Fei, Wang, Cai, Sun and Qi. This is an open-access article distributed under the terms of the Creative Commons Attribution License (CC BY). The use, distribution or reproduction in other forums is permitted, provided the original author(s) and the copyright owner(s) are credited and that the original publication in this journal is cited, in accordance with accepted academic practice. No use, distribution or reproduction is permitted which does not comply with these terms. 